\title{
Polyaniline as Novel Polymer Materials for Dry Electrode- Based Electrocardiography (ECG)
}

\author{
Jeffry Omega Prima, Bayu Pamungkas, Nugraha, Suprijanto * \\ Medical Instrumentation - Physics Engineering \\ Institute of Technology Bandung \\ TP Rachmat Building $3^{\text {rd }}$ floor (Labtek IV) Jalan Ganesa 10 \\ Bandung, Indonesia
}

\begin{abstract}
Electrocardiography (ECG) has been instrumental for early detection of cardiovascular anomalies. In this research, we successfully prototyped and evaluated the performance of a novel dry electrode as ECG sensor. Copper was selected as dry electrode material due to its good balance between conductivity and affordability. Polyaniline was used as a conductive coating to facilitate the conversion of ionic currents from the human body into electrical currents in electronic circuits. The coating was carried out via electrodeposition technique. Optimal electrodeposition time of 20 min using acetic acid as a dopant was established. This yields in the dry electrode with comparable performance to the certified wet electrode currently available in the market, shown by PQRST signal correlation between dry electrodes (this study) and the wet electrode (benchmark) which is close to zero. The dry electrode prototyped in this study is characterized to have a conductivity of $7 \times 10^{-4} \mathrm{~S} / \mathrm{mm}$, a resistance of $10 \Omega$, capacitive reactance of $140 \Omega$, and excellent signal stability showing a value of $256.5 \mu \mathrm{V}$ consistently for 2 hours.
\end{abstract}

Keywords: heart attack, early detection, electrocardiography (ECG), dry electrode, polyaniline, electrodeposition

\section{INTRODUCTION}

Cardiovascular disease (CVD) or generally known as heart disease has been regarded as the leading cause of death in Indonesia, approximated to reach $37 \%$ of the total recordable death. Studies suggest that CVD is heavily linked to, e.g. smoking and alcohol consumption habits, unhealthy diets, and sedentary behavior [1]-[5].

Electrocardiography (ECG) has been one of the most important techniques for early diagnosis of heart disease [6]-[8]. ECG is medical instrumentation to monitor the electrical activity of the heart within a certain period of time by placing an electrode in the patients' skin. These electrodes detect the minuscule electrical changes on the skin due to the activity of heart muscle during each heartbeat [9].

Nowadays, ECG sensors employ electrodes that can be categorized into either wet or dry electrodes. Wet electrodes are so named because of the wet electrolytic solution or gel included in the electrode [10]. This solution/gel is crucial to creating an interface between the patient's skin and the electrode. The electrodes usually yield in excellent ECG signals. Set up of ECG with wet electrode often involves long and uncomfortable preparation step. The preparation can be painful for the patient because it usually involves the abrasion of the patient's outer skin layer. Additionally, the gel used in ECG may exhibit allergic reactions or infections to patients with sensitive skin. Moreover, the transfer of ions from the bio-electric activity to the electrical current becomes disrupted because of the gel

\footnotetext{
* Corresponding Author. Email: supri@tf.itb.ac.id Received: April, 052018 Accepted: May, 082018

; Revised: April, 202018

; Published: August, 312018
} (C) 2018 PPET - LIPI concentration changes due to evaporation. This condition will lead to the decline in the quality of ECG signal measurements, thus reducing the accuracy of medical personnel in conducting interpretation of heart electrical signals for diagnostic purposes [11].

Dry electrode does not employ electrolytic solution or gel. Instead, it employs solid (dry) conducting polymers as an interface between patient's skin and ECG sensors. Advantages of the dry electrode to its wet counterparts are, amongst others, the possibility for multiple uses, rapid set-up, and minimum risk of infection to patients especially those with sensitive skin. Disadvantages of the current dry electrode are especially in the signal quality; it is unsuitable in the haired area because the electrode is not fully exposed to the skin [12], [13]. In line with the current field of materials research progress, the use of dry electrodes has become one of the most promising alternatives of the wet electrode in ECG application. The dry electrode in ECG is composed of a conductive polymeric material which is superimposed onto metal with excellent conductivity [14]. This conductive polymer material can conduct ionic currents from the patient's body so that a dry electrode can capture and convert to electrical current [15], [16]. Selection of bio-compatible materials can mitigate allergic reactions to patients with sensitive skins. Additionally, the use of dry electrode mitigates the risk of signal deterioration over time due to the elimination of gel [17].

In this study, we develop dry electrode which can be developed with material that can be obtained from the domestic market. Wet electrode present in the market is used as a benchmark to evaluate the performance of our dry electrode. 


\section{A. Schematic Diagram of ECG}

ECG consists of three main components, i.e. sensor, signal conditioning, and data representation. ECG's is electrodes that are connected by using a cable to the signal conditioner as shown in Figure 1.

Signal conditioning is required to amplify the signal received by electrodes. This is necessary because the heart's electrical signal is very small (in millivolt order of magnitude) so it can be easily concealed by measurement noise. The signal conditioning on ECG is differential amplifiers, analog to digital converter and filters. The signal conditioning on ECG must meet certain requirements, such as a minimum gain of 20 $\mathrm{mm} / \mathrm{mV}$ and a maximum error of $5 \%$ [18].

Data is generally presented in the form of displays (computer monitors) as well as print-out. The printing presentation data is usually needed to facilitate doctor to analyze and record the development of the heart's electrical signal from the patient.

\section{B. ECG Measurement}

Heart's muscles consist of muscle fibers that are electrically charged, linked to the presence of $\mathrm{Na}^{+}$ current from and to the cell. As a result, the heart undergoes depolarization and depolarization cycle continuously, which forms the heart's pulse pattern.

See Figure 2, the heart's bioelectric is raised by the sinoatrial node (SA node), atrioventricular node (AV node), and then propagates through the conduction cell called Purkinje fibers. After that, it flows into all parts of the heart to form an ECG signal complex [19]. The heart's electrical signal shown in Figure 3 is often called PQRST signal because the labeling of each peak on the signal is $\mathrm{P}, \mathrm{Q}, \mathrm{R}, \mathrm{S}$, and T. Peak $\mathrm{P}$ is caused by depolarization of atrium. The QRS complex is formed simultaneously which shows depolarization of the ventricle. The QRS complex is followed by the T wave that is repolarization of the ventricle. The $U$ wave following the $\mathrm{T}$ wave occurs due to repolarization of the Purkinje fibers.

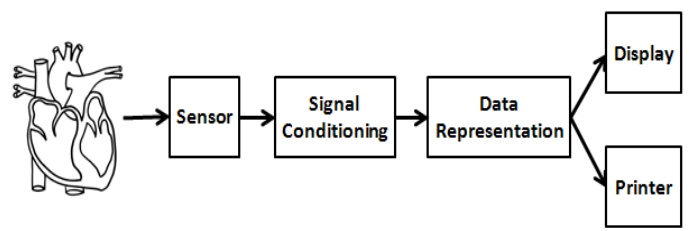

Figure 1. Schematic diagram of electrocardiography

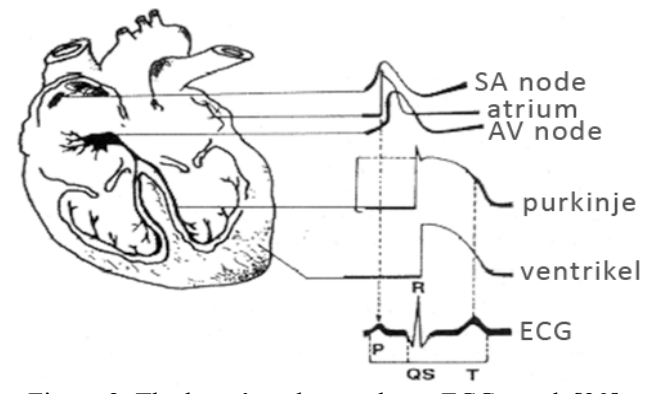

Figure 2. The heart's pulse produces ECG graph [20]

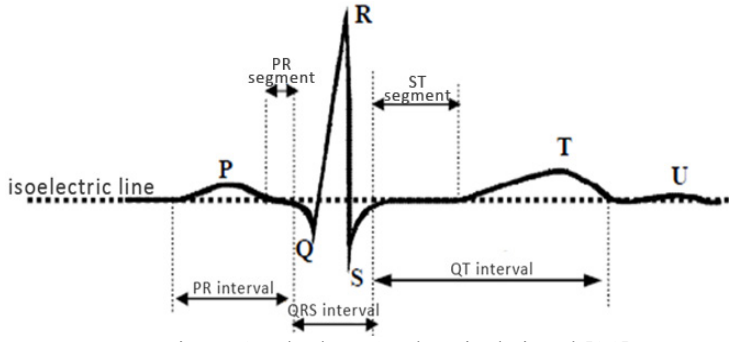

Figure 3. The heart's electrical signal [21]

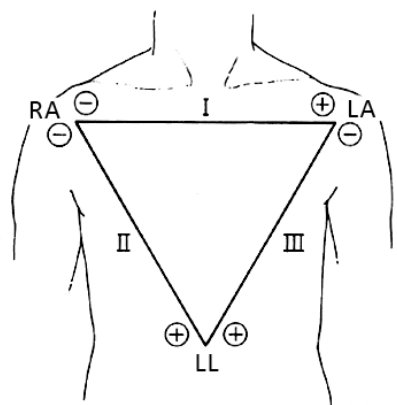

Figure 4. Schematic of standard bipolar lead

By analyzing the ECG graph, the abnormalities of the heart can be analyzed. This analysis involves 12 clinical criteria as outlined below:
1. Rhythm
7. Q interval
2. Frequency
8. R amplitude
3. P wave amplitude
9. ST segment
4. P wave duration
10. QT interval
5. PR interval
11. T amplitude
6. QRS interval
12. Regularity [19].

Leads on ECG can be categorized into three: i) standard bipolar lead, ii) unipolar lead, and iii) precordial lead (chest lead). The schematic of standard bipolar lead is shown in Figure 4. In this study, we have chosen standard bipolar lead for simple and fast in installation. Standard bipolar lead is commonly called Einthoven lead. This lead is determined by the potential difference between two particular points [22].

Lead I: The potential difference between the left arm (LA) and the right arm (RA).

Lead I = LA - RA

Lead II: The potential difference between the left leg (LL) and the right arm (RA).

$$
\text { Lead II }=\text { LL }- \text { RA }
$$

Lead III: The potential difference between left leg (LL) and left arm (LA).

$$
\text { Lead III }=\text { LL }- \text { LA }
$$

\section{ECG Electrode}

Types of electrode currently available in the market can be categorized into either wet electrodes or dry electrodes [10].

\section{1) Wet Electrode}

Biopotentials are electrical potentials inside the human body. Ions such as $\mathrm{Cl}^{-}, \mathrm{Ca}^{+}$, and $\mathrm{Na}^{+}$are used as charge transports in an organic system. In a sensing system, including ECG, electrons are used as the charge transport. Therefore, to measure biopotentials, ion currents from the body need to be transformed into electron currents [23]. 


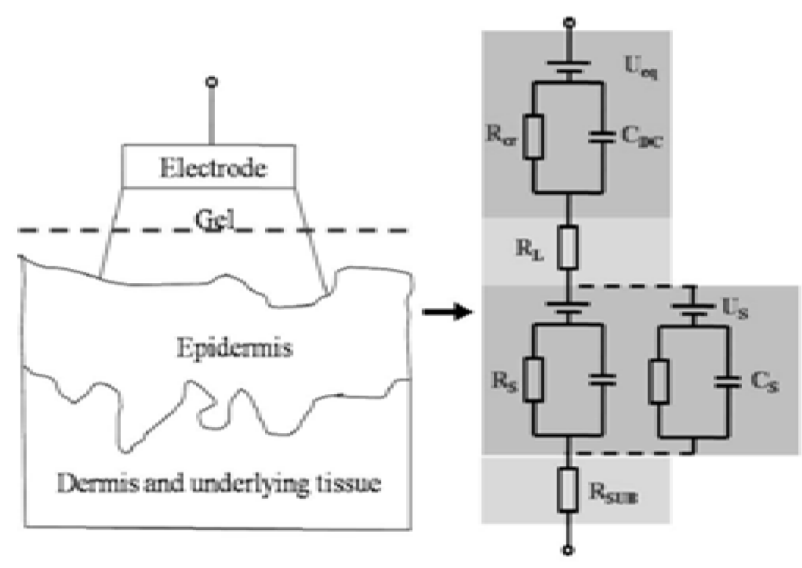

(a)

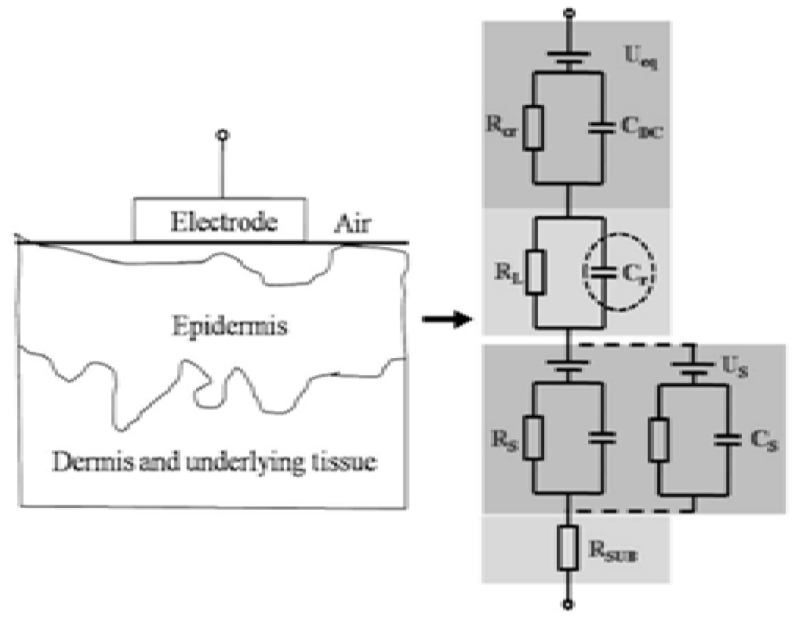

(b)

Figure 5. Schematic diagram and the equivalent circuit of a wet electrode-skin interface (a) and a dry electrode-skin interface (b)

The outer layer of the skin (stratum corneum) has a dry dielectric layer, which hampers the transfer mechanism from ions to electrons [24]. Because the few-polarizable $\mathrm{Ag} / \mathrm{AgCl}$ electrode is usually used as the conventional wet electrode, conduction gel has to be applied to moisturize the skin's outer layer and transform it into a highly ion-conductive layer. The equivalent circuit model of the skin-electrode interface for the conventional wet electrode is shown in Figure 5 [12]. Here, $C_{D C}$ denotes the double layer, $R_{C T}$ and $R_{L}$ the impedances of the electrode-electrolyte interface and the electrolyte, respectively, and $U_{e q}$ the electrode potential.

\section{2) Dry Electrode}

Unlike conventional wet electrode, dry electrode exhibits both polarization and conductivity due to the partly polarisable electric characteristic of electrically conductive polymer fabric [12], and it can provide a strong capacitive behavior at the interface [13]. The equivalent circuit model of our dry skin-electrode interface is shown in Figure 5 [12]. Here, $C_{T}$ is the equivalent capacitor at the interface. Therefore, biopotentials can be measured by the inductive method via $C_{T}$, and the influence of stratum corneum can be effectively reduced. Moreover, sweat and skin humidity can also form a conductive path $R_{L}$ [25]. The dry electrode can fit the scalp surface well to increase the contact area between skin and electrode to reduce the impedance $R_{L}$.

\section{Conductive Polymer}

The conductive polymer is a type of polymer that has electrical conductivity resembling the electrical conductivity of the metal compound. The conductive polymer occurs because of the presence of a double bond conjugated to a polymer chain. Conjugation systems occur on covalently bonded and single carbon atoms alternately $(\mathrm{C}=\mathrm{C}-\mathrm{C}=\mathrm{C}-\mathrm{C})$ and affect each other which forms the electron delocalization region. Electrons in the delocalization do not belong to one atom, but belong to the whole conjugate system. Moreover, the addition of a chemical compound in the form of doping may alter the electron density of the conjugated bond or polymer causing a change in the conductivity of the semi conductive polymer to a conductive polymer. Some examples of conductive polymers are polypyrrole, polyacetylene, and polyaniline [26].

\section{E. Electrodeposition}

Electroplating is often also called electrodeposition, a short version of electrolytic deposition, and the two terms are used interchangeably. As a matter of fact, electroplating can be considered to occur by the process of electrodeposition. It is a process using electrical current to reduce cations of a desired material from a solution and coat that material as a thin film onto a conductive substrate surface [27].

\section{METHOD}

\section{A. Preparation of Dry Electrode}

\section{1) Material selection}

Currently, dry electrodes are being studied in many countries due to the increasing need for biopotential electrodes. In this study, copper is selected as the material for the electrode. The reasoning is that copper has comparable conductivity to other metals with a considerably affordable price which is described in Table 1. Silver has higher conductivity than copper but with the expense of hundred-fold material price increase.

Metal, unfortunately, cannot convert ionic currents from the human body into electrical currents in electronic circuits. Therefore, copper alone cannot be used as an interface with the skin, it needs other materials as a coating. Polyaniline is selected as the coating material due to its conductive nature. Shown in Figure 6, polyaniline is a large molecule constructed by repeating small and simple chemical entities called aniline monomers $\left(\mathrm{C}_{6} \mathrm{H}_{5} \mathrm{NH}_{2}\right)$ that are covalently bonded to each other. Based on the degree of oxidation, polyaniline can be categorized into the fully reduced leucoemeraldine base (LB), semi-oxidized emulsed oxidized base (EB) and fully oxidized pernigraniline base (PB) [29], [30]. 
TABLE 1

The Conductivity of Metal And The Estimated PRICE [28]

\begin{tabular}{|l|c|r|}
\hline \multicolumn{1}{|c|}{ Metal } & $\begin{array}{r}\text { Conductivity } \\
(\mathbf{x 1 0} \mathbf{~} / \mathbf{m})\end{array}$ & Price per gram (IDR) \\
\hline Silver & 6.1 & 8100 \\
\hline Copper & 5.7 & 90 \\
\hline Gold & 4.1 & 580,000 \\
\hline Aluminium & 3.5 & 26 \\
\hline Zinc & 1.7 & 30 \\
\hline Brass & 1.1 & 54 \\
\hline
\end{tabular}

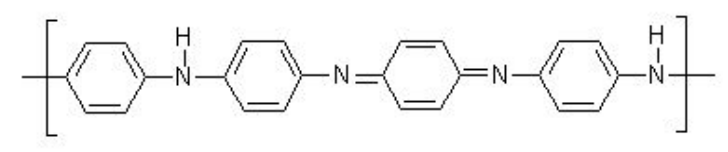

Figure 6. The chemical formula of polyaniline

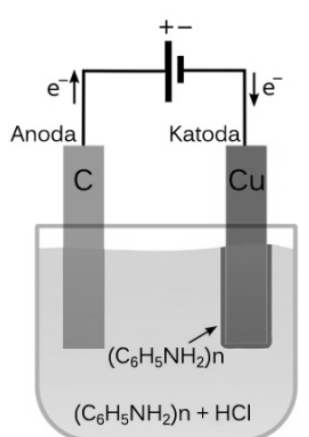

Figure 7. Schematic of dry electrode manufacturing via electrodeposition

In this study, EB polyaniline is selected because of its superior stability and conductivity properties. For the doping process in this study used two types of dopants namely hydrochloric acid $(\mathrm{HCl})$ and acetic acid $\left(\mathrm{CH}_{3} \mathrm{COOH}\right)$. Therefore, in the human body is dominated by $\mathrm{Cl}^{-}$ions and there is propionic acid $\mathrm{C}_{2} \mathrm{H}_{5} \mathrm{COOH}$.

The fabrication cost of making 15 dry electrodes using $\mathrm{HCl}$ dopant requires about 300,000 IDR. The copper needed to make one electrode about 5 grams (450 IDR), $4 \mathrm{~mL} \mathrm{HCl} 1 \mathrm{M}$ (1,000 IDR), 1.82 grams aniline (20,000 IDR) and electricity about 3,000 IDR. The price of the disposable electrode on the market is 4,000 IDR, compared to the electrode made in this study which only requires about 2,000 IDR per electrode is much cheaper and has the advantage of solution can be used to make more than 15 electrodes.

\section{2) Dry Electrode Manufacturing \\ Electrodeposition}

Via

Polyaniline coating on copper is carried out by electrodeposition method which is shown in Figure 7. In the electrodeposition process, copper is placed on the cathode and carbon (inert) on the anode. Aniline is acidified (doped/dissolved) in $\mathrm{HCl}$ or $\mathrm{CH}_{3} \mathrm{COOH}$.

The reaction occurring at the cathode is as follows:

$$
\mathrm{Cu}^{2+}+2 \mathrm{e}^{-} \leftrightarrow \mathrm{Cu}
$$

Meanwhile, at the anode, water is oxidized:

$$
2 \mathrm{H}_{2} \mathrm{O} \leftrightarrow 4 \mathrm{H}^{+}+\mathrm{O}_{2}+4 \mathrm{e}^{-}
$$

Due to external electric current, aniline monomer will migrate to the cathode and polymerize into polyaniline and the $\mathrm{H}^{+}$will increase frequently with increasing time. The thickness of the polyaniline layer increases with the increase of electrodeposition duration.

For acidified aniline using $\mathrm{HCl}$ dopant, it required 1.82 grams of aniline, $4 \mathrm{~mL}$ of $\mathrm{HCl} 12 \mathrm{M}$, and $50 \mathrm{~mL}$ water. For acidified aniline using $\mathrm{CH}_{3} \mathrm{COOH}$ as the dopant, it takes 1.82 grams of aniline, $3 \mathrm{~mL}$ of $\mathrm{CH}_{3} \mathrm{COOH} 98 \%$, and $50 \mathrm{~mL}$ of $\mathrm{H}_{2} \mathrm{O}$. Electric current with $4 \mathrm{~V}$ voltages is generated by a power supply and fed into the cathode and anode. Electrodeposition duration is varied between 10 and $30 \mathrm{~min}$ to obtain different polyaniline thickness.

\section{B. ECG Set-up}

ECG configuration consists of three major components, there are presentation data, signal conditioning, and sensors. For this study, dry electrodes (copper metal coated with polyaniline) were used as the sensor. Signal conditioning, Olimex Open EEG-SMT is used as a differential amplifier and analog filter. A laptop is used as a display.

\section{1) Hardware}

The hardware used in this research is in the signal conditioning and sensor parts. At the signal conditioner used Olimex Open EEG-SMT while on the sensor using dry electrode.

Olimex Open EEG-SMT is a module unit used for Electroencephalography (EEG), which detects recording of the activity of the district along the scalp to detect brain signals. However, in this research is used to detect recording cardiac electrical activity or ECG. The advantages of Olimex Open EEG-SMT are relatively cheaper compared to other professional ECG devices, compact size, and open hardware [31].

\section{2) Software}

The software used in this research is Open Source BrainBay 1.9. Open Source BrainBay is a Bio and Neurofeedback application designed to work with OpenEEG-Hardware, ModularEEG, and MonolithEEG. The function of Open Source BrainBay is used as Human-Computer-Interface (HCI) and NeuroServer Software Framework to transmit recording over the internet or LAN. Open Source BrainBay is part of the OpenEEG project and provides graphical feedback [32].

\section{Dry Electrode Characterization and Performance Tests}

To evaluate the characteristics and the performance of the designed dry electrode, three types of tests were carried out, i.e. conductivity test, PQRST signal testing, and stability test.

\section{1) Conductivity test}

Conductivity test is carried out using LCR meter tool to quantify the impedance and assess the phase. From the measured impedance and phase gives the real and imaginary values, this can be converted into resistance and capacitance of the dry electrode. Furthermore, from the value of resistance, resistivity and conductivity values can also be determined. The resistance, capacitance, and conductivity values are 
important to assess whether the prototyped dry electrodes meet the minimum specifications as ECG sensor or not.

\section{2) PQRST signal testing}

PQRST signal testing is carried out using Olimex Open EEG-SMT hardware and Open Source BrainBay software as described earlier. Subsequently, the measured PQRST signal of the dry electrode is benchmarked with the certified disposable wet electrodes available in the market.

\section{3) Stability test}

In the stability test, we used generator signal and voltage divider circuit to get the data. Generator signal is set to give a digital signal with a certain frequency. Then, it is connected to the voltage divider circuit to prepare the voltage entered into ECG. In BrainBay, the changing of amplitude voltage is watched out every 10 min for 2 hours.

\section{RESUlt AND ANALYSIS}

\section{A. Conductivity Test Result}

Figure 8 shows the impedance phasor for copper consists of resistive and capacitive components. The resistive and capacitive components are arranged in series. It is explained that to be a biopotential electrode the resistive and capacitive components must be assembled in parallel to obtain only low frequencies. The disposable electrodes same as copper consisted of resistive and capacitive components but arranged in parallel to fit the biopotential electrodes.

Dry electrodes produced using $\mathrm{HCl}$ as dopant and electrodeposition processes for 10, 25, and 30 min have resistive and capacitive components shown in Figure 9a. Electrodeposition duration of 25 and 30 min produces an electrode with the resistive and capacitive components arranged in series. Meanwhile, electrodeposition duration of $10 \mathrm{~min}$ produces an electrode with the resistive and capacitive components arranged in parallel but has a value of capacitive resistance and reactance greater than the disposable electrode. This will affect the PQRST signal with lower amplitude due to the effect of the large resistance value. The frequency may also be truncated due to the large capacitive reactance value.

Dry electrodes produced with $\mathrm{CH}_{3} \mathrm{COOH}$ as the dopant has resistive and capacitive components. Figure $9 \mathrm{~b}$ shows the electrodeposition duration of $20 \mathrm{~min}$ produces an electrode with an impedance phasor approaching the impedance phasor of the disposable electrodes. The electrode also has slightly higher resistance than wet electrode $(10 \Omega)$, which is expected to give lower amplitude in PQRST signal. In addition, this electrode has much higher capacitive reactance value resulting in a partial cut of frequency values so that the PQRST signal looks smoother.

Figure 10 shows the conductivity characteristics of the produced dry electrodes. The highest conductivity value of the dry electrode is $5 \times 10^{-2} \mathrm{~S} / \mathrm{mm}$, much higher than the benchmark (certified disposable wet electrodes available in the market), which is only $7 \times 10^{-4} \mathrm{~S} / \mathrm{mm}$.
To obtain the dry electrode with comparable conductivity value to benchmark, electrodeposition time of the dry electrode should be set to $20 \mathrm{~min}$ with $\mathrm{CH}_{3} \mathrm{COOH}$ used as the dopant. The resulting dry electrode has conductivity value of $6 \times 10^{-4} \mathrm{~S} / \mathrm{mm}$. Judging from the conductivity value, the dry electrode that can replace the disposable electrodes are dry electrode using $\mathrm{CH}_{3} \mathrm{COOH}$ dopant with $20 \mathrm{~min}$ electrodeposition process.

\section{B. PQRST Signal Test Result}

Figure 11 shows PQRST signal from the copper closet to the PQRST signal from the disposable electrodes but in both there is noise affecting the $\mathrm{P}$ wave and $\mathrm{T}$ wave so it can change its true shape and make the result in analyzing the heart abnormality will be difficult. In addition, in copper to obtain the PQRST signal it takes a longer time because copper requires sweat coming out of the body instead of the gel in wet electrodes and copper is more difficult to experience a reduction-oxidation reaction.

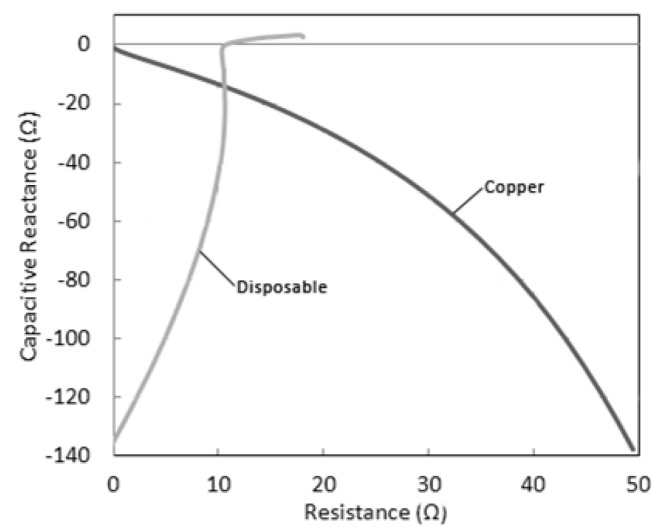

Figure 8. Phasor diagram of resistance, reactance and impedance for copper and disposable electrodes

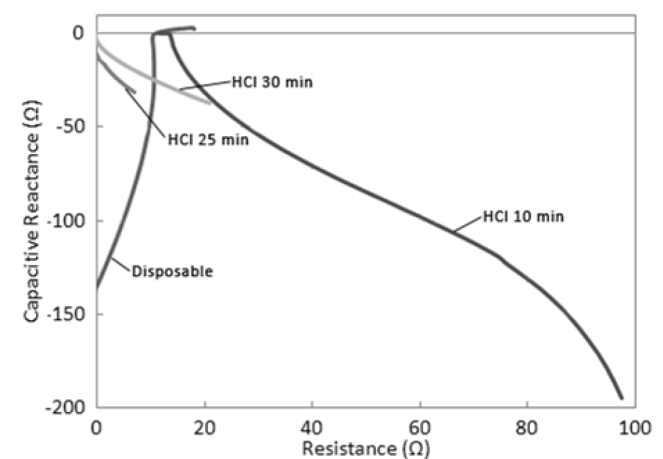

(a)

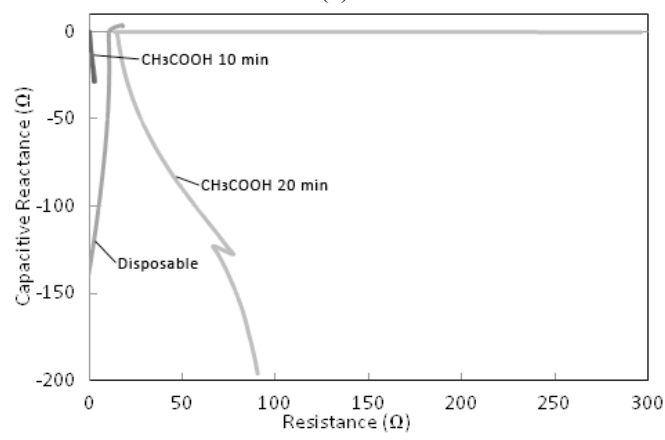

(b)

Figure 9. Phasor diagram of resistance, reactance and impedance of dry electrodes (a) using $\mathrm{HCl}$ dopant (b) using $\mathrm{CH}_{3} \mathrm{COOH}$ dopant compared to disposable electrodes as a benchmark 


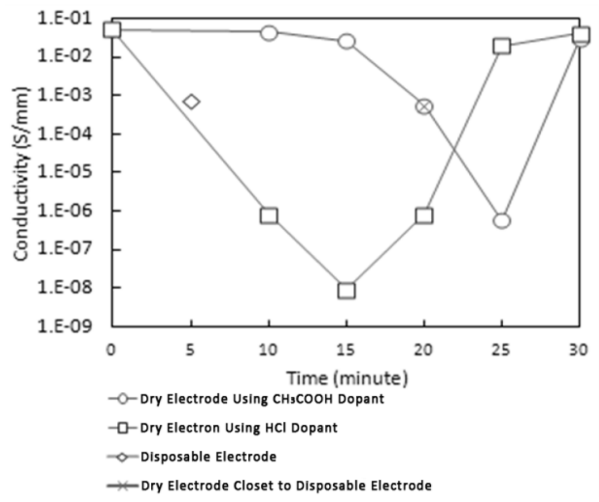

Figure 10. The graph of conductivity against electrodeposition time

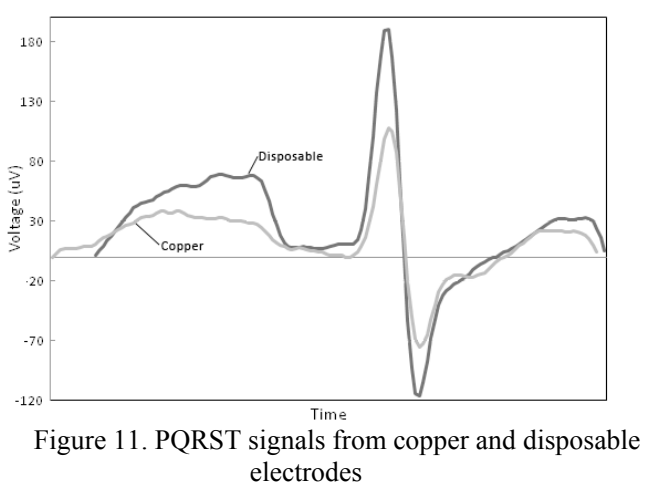

When the dry electrodes are produced with $\mathrm{HCl}$ as a dopant, the quality of PQRST signal was declining with the increasing electrodeposition duration. To obtain PQRST signal resembling the benchmark, electrodeposition duration should be set between 10 and 25 min which is shown in Figure 12a. This yields in the electrode with a noticeable difference only in $\mathrm{P}$ wave and amplitude R. P wave and R amplitude is essential

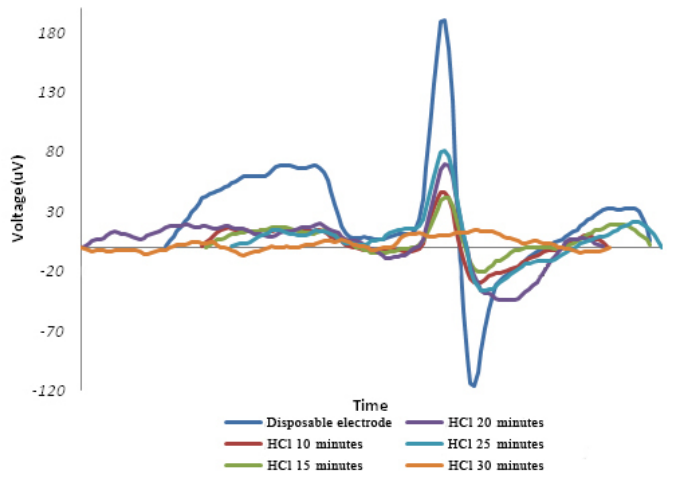

(a) for doctors as tools to analyze some heart abnormalities. However, these dry electrodes are good enough to be used to replace present wet electrodes. When $\mathrm{CH}_{3} \mathrm{COOH}$ is used as the dopant, the tendency is similar to that with $\mathrm{HCl}$ as the dopant, where the quality of PQRST signal declines with increasing electrodeposition duration. Shown in Figure 12b, dry electrode produced with electrodeposition duration of 10,15 , and $20 \mathrm{~min}$ also exhibit noticeable difference with benchmark in wave $\mathrm{P}$ and amplitude $\mathrm{R}$. Electrodeposition duration of $20 \mathrm{~min}$ appears to produce the dry electrode with PQRST signal with $\mathrm{P}$ wave and amplitude $\mathrm{R}$ also comparable to the benchmark. The dry electrode produced with electrodeposition duration of 30 min produces PQRST signal that is not visible at all because it is covered by noise. Therefore, it is concluded that electrodeposition duration of $20 \mathrm{~min}$ with $\mathrm{CH}_{3} \mathrm{COOH}$ as the dopant is the most suitable process to produce the dry electrode that fit best to replace the current wet electrode. The fitness of PQRST signal between this dry electrode and the benchmark is shown in Figure 12c, there is $84 \%$ compared to $60 \%$ when the copper dry electrode is not coated with polyaniline.

\section{Stability Test Result}

It can be seen in Figure 13 that for dry electrodes using $\mathrm{HCl}$ or $\mathrm{CH}_{3} \mathrm{COOH}$ dopant are very stable, showing voltage values of $256.5 \mu \mathrm{V}$ for 2 hours consistently. Electrodeposition duration appears to give negligible impact to electrode stability; the indicated voltage value is still very similar. Therefore, compared with the wet electrodes, dry electrodes appear to be more promising in term of measurement stability.

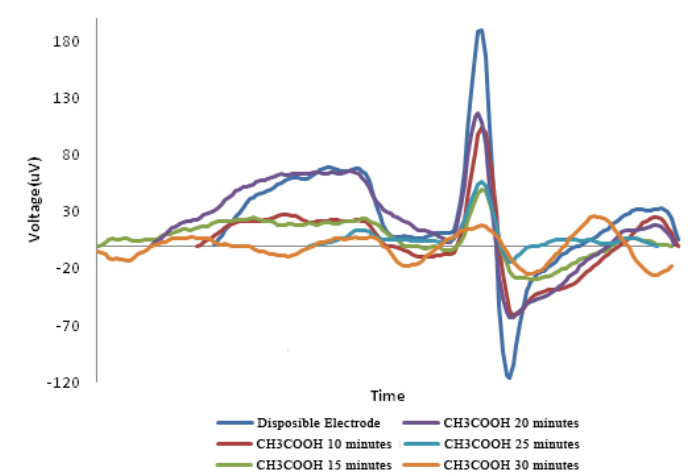

(b)

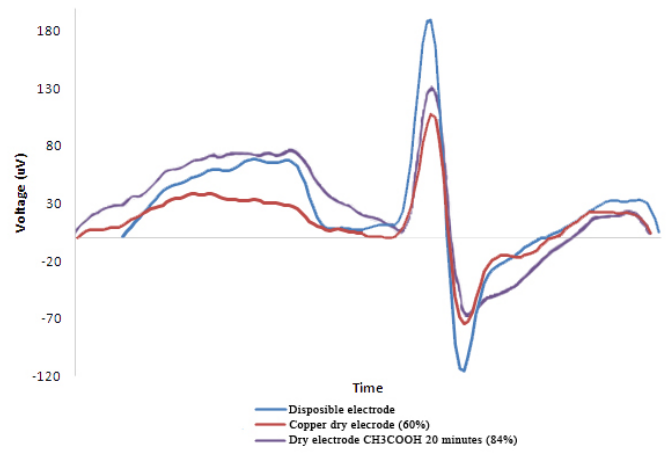

(c)

Figure 12. PQRST signal (a) dry electrodes using $\mathrm{HCl}$ dopant, (b) dry electrodes using $\mathrm{CH}_{3} \mathrm{COOH}$ dopant compared to disposable electrodes as a benchmark and (c) disposable electrode with the dry electrode coated with polyaniline (84\%) and copper dry electrode $(60 \%)$ 


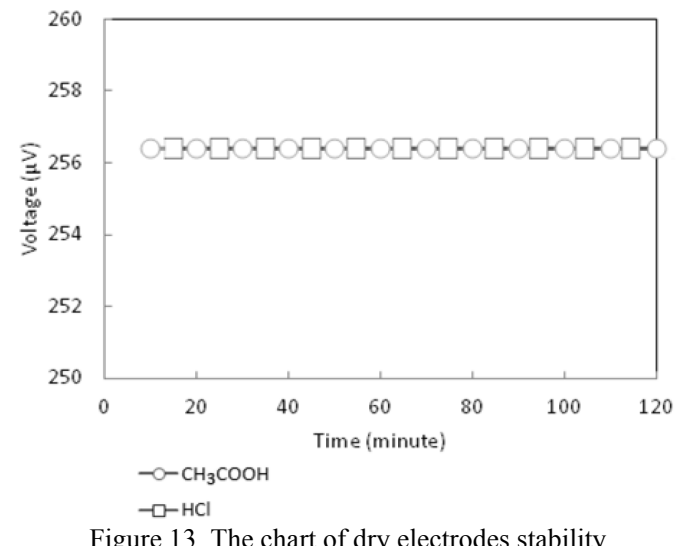

Figure 13 . The chart of dry electrodes stability

\section{CONCLUSION}

In this study, the dry electrode for ECG based on copper and coated with polyaniline has been prototyped, characterized, and benchmarked to wet electrode available in the market.

The conductivity of dry electrodes using $\mathrm{HCl}$ and $\mathrm{CH}_{3} \mathrm{COOH}$ dopant has resistive and capacitive components. Especially, the dry electrode with $\mathrm{CH}_{3} \mathrm{COOH}$ as a dopant and the electrodeposition duration of $20 \mathrm{~min}$ has resistive and capacitive components arranged in parallel higher resistance and capacitive reactance so it gives lower amplitude give lower amplitude and smoother in PQRST signal. Dry electrodes produced with $\mathrm{HCl}$ as dopant during electrodeposition process shows good comparability to PQRST signal of the benchmark with noticeable difference in with $\mathrm{P}$ wave and amplitude $\mathrm{R}$. When $\mathrm{CH}_{3} \mathrm{COOH}$ is used as dopant, the tendency is similar to that with $\mathrm{HCl}$ as dopant except when the electrodeposition time is set to $20 \mathrm{~min}$, where the $\mathrm{P}$ wave and amplitude $\mathrm{R}$ of the PQRST signal is also relatively similar to the benchmark. Therefore, it is concluded that electrodeposition duration of $20 \mathrm{~min}$ with $\mathrm{CH}_{3} \mathrm{COOH}$ as a dopant is the most optimum parameters to produce the dry electrode to replace available wet electrode. Electrodeposition time and dopant used $\left(\mathrm{HCl}\right.$ or $\left.\mathrm{CH}_{3} \mathrm{COOH}\right)$ appear to give no impact on the stability of the resulting dry electrode. The electrode shows very stable voltage values for at least 2 hours. Due to its superior stability, the prototyped dry electrode can be suitable for routine and repetitive ECG measurements.

\section{REFERENCES}

[1] L. Riley and M. Cowan, Noncommunicable Disease (NCD) Country Profiles, World Health Organization, Geneva, Switzerland, 2014

[2] J. Arnlov, et al., "Impact of body mass index and the metabolic syndrome on the risk of cardiovascular disease and death in middle-aged men," AHA J., vol.121, pp. 230-236, Jan. 2010.

[3] E. G. Wilmot, et al., "Sedentary time in adults and the association with diabetes, cardiovascular disease and death: systematic review and meta-analysis," Diabetologia, vol. 55, no. 11, pp. 2895-2905, Aug. 2012.

[4] L. Erhardt, "Cigarette smoking: An undertreated risk factor for cardiovascular disease," Atherosclerosis, vol. 205, pp. 23-32, Jul. 2009.

[5] Prospective Studies Collaboration, "Body-mass index and cause-specific mortality in 900000 adults: collaborative analyses of 57 prospective studies," The Lancet, vol. 373, no. 9669, pp. 1083-1096, Mar. 2009.
[6] G. Schillaci, et al., "A review of the role of electrocardiography in the diagnosis of left ventricular hypertrophy in hypertension," J. Electrocardiology, vol. 45, no. 6, pp. 617623, Nov 2012.

[7] M. AlGhatrif, et al., "A brief review: history to understand fundamentals of electrocardiography," J. Community Hosp. Intern. Med. Perspect., vol. 2, pp. 14383-14388, Apr. 2012.

[8] D. Pewsner, et al., "Accuracy of electrocardiography in diagnosis of left ventricular Hypertrophy in arterial hypertension," $B M J$, vol. 335, pp. 711-719, Jul. 2007.

[9] Wikipedia. (2017) Electrocardiography. [Online]. Available: https://en.wikipedia.org/wiki/Electrocardiography

[10] J. R. Schofield, "Electrocardiogram signal quality comparison between a dry electrode and a standard wet electrode over a period of extend wear," M.S. Thesis, College Education Human Services, Cleveland State Univ., 2012.

[11] C. T. Lin, et al., "Novel dry polymer foam electrodes for longterm EEG measurement," IEEE Trans. Biomed. Eng., vol. 58, no. 5, pp. 1200-1207, May 2011.

[12] L. Beckmann, et al., "Characterization of textile electrodes and conductors using standardized measurement setups," Physiol Meas., vol. 31, no. 2, pp. 233-247, Jan. 2010.

[13] J. G. Webster, Medical Instrumentation: Application and Design, 3rd ed. Hoboken, New York: Wiley, 1998.

[14] R. Balint, N. J. Cassidy, and S. H. Cartmell, "Conductive polymers: Towards a smart biomaterial for tissue engineering," Acta Biomater., vol. 10, pp. 2341-2353, Jun. 2014.

[15] G. Kaur, R. Adhikari, P. Cass, M. Bown, and P. Gunatillake, "Electrically conductive polymers and composites for biomedical applications," RSC Adv., vol. 5, pp. 37553-37567, 2015.

[16] Y. Zare and I. Shabani, "Polymer/metal nanocomposites for biomedical applications," Mater. Sci. Eng. C Mater. Biol. Applicat., vol. 60, pp. 195-203, March 2016.

[17] L. S. Hsu, et al., "Developing barbed microtip-based electrode arrays for biopotential measurement," Sensors, vol 14, pp 12370-12386, Jul. 2014.

[18] M. R. Neuman, "Biopotential amplifiers," in Medical Instrumentation: Application and Design, pp 241-292, Feb 2008.

[19] E. S. Nugroho, et al., "Pengenalan pola sinyal elektrokardiograf (EKG) dengan jaringan syaraf tiruan backpropagation untuk diagnosa kelainan jantung manusia," Undergraduate Thesis, Electrical Eng. Dept., Diponegoro Univ., Semarang, Jan. 2011.

[20] S. Karim, et al., "EKG dan penanggulangan beberapa penyakit jantung untuk dokter umum," FKUI Press, 1996.

[21] J. A. Akinsanya, "Principles of Biomedical Engineering for Nursing Staff," J. Advanced Nursing, vol. 20, pp. 779, 1994.

[22] A. N. Bakpas, et al., "Identifikasi karakter temporal dan potensial listrik statis pada elektrokardiografi (EKG) akibat penyakit otot jantung myocardial infarction (MI)," Undergraduate Thesis, Physic Dept., Hasanuddin Univ., Makassar, Aug. 2014.

[23] M. R. Neuman, "Biopotential electrodes," in Medical Instrumentation: Application and Design, pp 189-240, Feb. 2008.

[24] C. T. Lin, et al., "Noninvasive neural prostheses using mobile and wireless EEG," in Proc. IEEE, vol. 96, pp. 1167-1183, Jul. 2008.

[25] G. Medrano, et al., "Skin electrode impedance of textile electrodes for bioimpedance spectroscopy," in Proc. $13^{\text {th }}$ Int. Conf. Elect. Bioimpedance and the $8^{\text {th }}$ Conf. Elect. Impedance Tomography, 2007, vol. 17, pp. 260-263.

[26] B. Sitorus, et al., "Sintesis polimer konduktif sebagai bahan baku untuk perangkat penyimpanan energi," ELKHA J., vol 3, pp 43-47, Mar 2011.

[27] L. J. Durney, Electroplating Engineering Handbook, 4th Ed., Van Nostrand Reinhold Co., pp 364, 1984.

[28] E. Sutadi. (2015). Bahan-bahan Listrik [Online]. Available: http://www.academia.edu/5727777/bahanbahan_listrik_Bahan_Penghantar

[29] P. T. Bray, et al., "Sweat testing for cystic fibrosis," Arch. Dis. Child., vol 53, pp 483-486, 1978.

[30] O. Mickelsen, and A. Keys, "The composition of Sweat, with special reference to the vitamins," M.S. Thesis, Physiological Dept., Minnesota Univ., May 1943. 
[31] EEG-SMT Development Board User’s Manual, OLIMEX Ltd, [32] BrainBay - User Manual, ver. 1.9, BrainBay Ltd, 2014. 2011. 